\title{
Association of $\mathrm{LH} / \mathrm{FSH}$ ratio with menstrual cycle regularity and clinical features of patients with polycystic ovary syndrome
}

\author{
Maja Mitrašinović-Brulić ${ }^{10}$, Mihaela Buljan ${ }^{2}$ (D) and Damir Suljević ${ }^{*}$ (1)
}

\begin{abstract}
Background: Understanding the global prevalence and phenotypic features of polycystic ovary syndrome (PCOS) is important as geographic factors and ethnic variations can significantly alter the clinical syndrome. The aim of this study was to determine and evaluate the luteinizing hormone/follicle-stimulating hormone ratio (LH/FSH) in women with PCOS during therapy on selected endocrine and biochemical parameters.

Results: Women with PCOS were included in the study and were classified into two groups: women without therapy (de novo) and women with therapy for PCOS. ESHERE/ASRM criteria that require the presence of two out of three criteria: ovulatory dysfunction, hyperandrogenism, and morphological PCOS detected by ultrasound diagnostics. Electrochemiluminescence immunoassay (ECLIA) was used for FSH and insulin analysis. The enzymatic method was used to analyze the biochemical profile. There was a significant difference between the two groups in terms of the LH/FSH ratio (2.56 vs. 2.41, $P=0.043$ ), glucose (6.23 vs. $5.12, P=0.003$ ), insulin (19.21 vs. $7.35, P=0.000)$, IR (3.22 vs. 1.42, $P=0.000$ ), cholesterol (5.97 vs. $4.92, P=0.002)$, and $L D L(3.56$ vs. $2.56, P=0.001)$. The data suggest that patients with PCOS therapy have reduced hyperinsulinemia and insulin resistance. There was a significant correlation between the LH and FSH in the de novo group, as well as the correlation between hormone levels and LH/FSH ratio in both groups. Patients with PCOS therapy have a tendency for normal body weight and reduction of severe obesity compared to patients without therapy. Clinical features such as regular menstrual cycle and the prevalence of acne and hirsutism are not significantly different between groups.

Conclusion: PCOS cause irregularities of the menstrual cycle, the appearance of clinical manifestations, especially changes of LH/FSH ratio. Therapy for PCOS contributes to better regulation of endocrine and biochemical parameters, especially in the reduction of hyperinsulinemia, insulin resistance, and reduced LH/FSH ratio.
\end{abstract}

Keywords: Polycystic ovary syndrome, Insulin resistance, Body mass index, Obesity, Cholesterol

\section{Background}

Polycystic ovary syndrome (PCOS) is an endocrine disorder in reproductive women with variable prevalence (6-25\%). The main clinical manifestations of PCOS are represented by reproductive and metabolic disorders that do not necessarily occur simultaneously

\footnotetext{
*Correspondence: suljevic.damir@gmail.com; damir.suljevic@pmf.unsa.ba

${ }^{1}$ Department of Biology, Faculty of Science, University of Sarajevo,

Sarajevo, Bosnia and Herzegovina

Full list of author information is available at the end of the article
}

[1]. Reproductive disorders include polycystic ovaries, menstrual dysfunction, hyperandrogenism, hirsutism, infertility, gestational diabetes, ovulatory disfunction, neonatal complications, and pregnancy hypertension [2]. Metabolic disorders are often associated with and lead to the development of metabolic syndrome (MetS). Its features include obesity, insulin resistance (IR), hypertension, hyperlipidemia, and diabetes [3]. Metabolic disorders stimulate the development of cardiovascular and oncological diseases. The short-term and long-term health risks of such clinical manifestations of 
PCOS depend on race, ethnicity, geographical area, and environmental factors (physical activity, diet, stress, etc.) [4]. Insulin resistance is the main factor in the etiology of metabolic and reproductive complications of PCOS and is considered a multisystem endocrinopathy [5]. Insulin resistance develops before puberty and is a precursor for the development of polycystic ovary syndrome. Clinical features include black acanthosis, metabolic syndrome, sleep-disordered breathing, and nonalcoholic fatty liver disease [6]. Sleep-disordered breathing includes obstructive apnea and the most common predictors are plasma insulin concentrations and the glucose-insulin ratio [7]. Fatty liver disease (nonalcoholic) is associated with insulin resistance and dyslipidemia, and its prevalence is elevated in women with polycystic ovary syndrome [6]. The incidence of metabolic syndrome is due to the interaction of insulin resistance, increased body weight, and age. Insulin resistance, obesity, cardiovascular problems, and psychological issues are co-morbidities [8]. Approximately $60 \%$ of women with PCOS are hirsute, the most common clinical sign of hyperandrogenemia [9]. Hyperandrogenism encompasses clinical and biochemical characteristics such as androgen excess, which is a major endocrine disorder in PCOS [10, 11]. The symptoms of hyperandrogenemia are physiologically alleviated and the incidence of ovulation is more frequent after the age of forty. Thus, the incidence of the syndrome is reduced by $10 \%$ during perimenopause [12]. Gynecologically, PCOS includes reproductive organ damage, reduced fertility, ovarian cancer, and the incidence of preterm birth [13]. Irregularity in the secretion of gonadotropin-releasing hormone $(\mathrm{GnRH})$ is one of the factors for the development of PCOS, due to the reduced release of LH and FSH which causes a decrease in egg production [14]. Amenorrhea develops during a disturbed menstrual cycle [15].

Hypothalamic insensitivity to progesterone contributes to abnormal GnRH and gonadotropin secretion, reduced follicle development, and increased androgen production in the ovaries [16]. The initial disorder in PCOS can occur during fetal intrauterine life, and its consequences are present in postmenopause [17]. PCOS is caused by many factors, such as thyroid dysfunction, androgen-related tumors, exposure to chemicals, and overuse of cosmetics [18]. Genetic and epigenetic factors are involved in theca follicle dysfunction and adrenal steroidogenesis. 11 $\beta$-Hydroxysteroid dehydrogenase type 1 (11 $\beta$-HSD type 1$)$ deficiency disables the conversion of cortisone to cortisol, increasing adrenocorticotropic hormone (ACTH) which stimulates androgen production and leads to expression of the PCOS phenotype [19]. This study presents the first data for women diagnosed with PCOS in Bosnia and Herzegovina.

The study aims to first determine serum levels of biochemical parameters in de novo patients and patients with therapy for PCOS, and second, determine the incidence of abnormal luteinizing hormone/follicle-stimulating hormone (LH/FSH) ratio and therapeutic effects in the regulation of hormone levels in PCOS patients.

\section{Methods}

\section{Study participants and inclusion criteria}

This study included 150 fertile women with a diagnosed polycystic ovary syndrome (PCOS). The diagnosis was determined by ESHERE/ASRM criteria [10]. Participants were divided into two groups of 75 participants. The first group (group I, $\mathrm{G}_{1}$ ) is a control group with de novo diagnosed PCOS, without therapy involved. The second group (group II, $\mathrm{G}_{2}$ ) consists of patients with PCOS therapy. Metformin $500 \mathrm{mg}(2 \times 1)$ and myoinositol 1000 mg $(2 \times 1)$ are recommended. In the case of HOMA-IR 2.9 , the recommended dose of metformin is $3 \times 1$. During therapy, patients underwent regular check-ups every 4 months. At the end of the fourth month of therapy (group II), patients were included in the study. Diagnosed PCOS and informed consent of all participants are criteria for inclusion in the study.

\section{Database pre-screening and polycystic ovary syndrome diagnostic criteria}

Demographic and clinical parameters for patients in these studies were taken from the database of the Agram Polyclinic in Sarajevo (Bosnia and Herzegovina). Completed blood tests to measure hormone levels, transvaginal ultrasound to imaging of the ovaries, and a thorough personal and family history were required to confirm the PCOS diagnosis.

PCOS was diagnosed using ESHERE/ASRM criteria that require the presence of two out of three criteria (according to the Rotterdam consensus): ovulatory dysfunction, hyperandrogenism, and morphological PCOS detected by ultrasound diagnostics [10].

\section{Body mass index measurements}

Body mass index (BMI) was defined as the ratio of body weight to body height squared, expressed in $\mathrm{kg} / \mathrm{m}^{2}$. BMI was determined with a standard BMI calculator (Espanola). After the measurement, BMI categories were determined according to the manufacturer: underweight $\leq 18.5$, normal weight $18.5-24.9$, overweight $25-29.9$, and obesity $=\mathrm{BMI}$ of 30 or greater. 


\section{Insulin resistance measurements}

A homeostatic model (HOMA-IR) was used to assess insulin resistance. HOMA-IR is calculated as HOMA-IR $=$ insulin $(\mathrm{mU} / \mathrm{L}) \times$ glucose $(\mathrm{mg} / \mathrm{dL})$. The homeostatic model calculates beta-cell function (\% B) and insulin sensitivity (\% S) as a percentage. A healthy range is $0.5-1.4$. Less than 1.0 means the patient is insulin-sensitive, above 1.9 indicates early insulin resistance, and above 2.9 indicates significant insulin resistance.

\section{Electrochemiluminescence immunoassays}

Luteinizing hormone ( $\mathrm{LH})$, follicle-stimulating hormone (FSH), and LH/FSH ratio were measured when considering a PCOS diagnosis. Electrochemiluminescence immunoassay (ECLIA) was used for FSH analysis. The Elecsys LH assay employs two monoclonal antibodies specifically directed against human LH [20]. The results were measured on a calibration curve using a Cobas e 411 analyzer (Roche Diagnostics, Germany).

\section{Elevated LH/FSH ratio}

The luteinizing hormone/follicle-stimulating hormone ( $\mathrm{LH} / \mathrm{FSH})$ ratio is often requested to help diagnose PCOS despite a recent consensus recommending against its use. In healthy women, the ratio between $\mathrm{LH}$ and FSH usually lies between 1 and 2, and in PCOS women, this ratio becomes reversed, and it might reach as high as 2 or 3 [21].

\section{Glucose levels and insulin profile}

Serum glucose levels were measured using the enzymatic UV method with hexokinase. Glucose-6-phosphate formed from glucose and ATP by hexokinase is oxidized by NAD in a reaction catalyzed by glucose-6-phosphate dehydrogenase to create $\mathrm{NADH}$, which is quantitated spectrophotometrically at $340 \mathrm{~nm}$. An Olympus AU400 automated chemistry analyzer was used to measure serum glucose levels and commercial kits (Roche, Manheim, Germany)

Serum insulin level was measured using commercial kits and an electrochemiluminiscence device (Elicsys, Roche Diagnostics). The method is based on the binding of insulin to a specific monoclonal antibody labeled with ruthenium with the addition of streptavidin-coated microparticles. The application of voltage to the electrodes induces chemiluminescent emission measured by a photomultiplier.

Glucose and insulin levels were measured in venous blood on an empty stomach and the second evaluation $120 \mathrm{~min}$ after taking $75 \mathrm{~g}$ of glucose.

\section{HDL and LDL cholesterol measurements}

Women with PCOS have a greater tendency to have high cholesterol (lower levels of high-density lipoproteins or HDL and higher levels of low-density lipoproteins or LDL) [22]. Besides, triglyceride levels, another component of cholesterol, tend to be high in women with PCOS. Cholesterol esterase is mainly used in clinical studies to determine the level of cholesterol in human blood. The determination is based on the method of Allain et al. [20] that monitors generated free cholesterol in the reaction catalyzed by cholesterol oxidase. Color intensity is directly proportional to the amount of cholesterol, with maximum absorption at the wavelength of $500 \mathrm{~nm}$.

Enzymatic hydrolysis of serum triglycerides by lipoprotein lipase generates free fatty acids and glycerol, with an absorbance maximum at $540 \mathrm{~nm}$.

$H D L$ and $L D L$ cholesterol are measured directly in the serum. Sulfated alpha-cyclodextrin in the presence of $\mathrm{Mg}^{2+}$, which forms complexes with apoB. This complex contains lipoproteins and polyethylene glycol-coupled cholesterol esterase and cholesterol oxidase to measure HDL-cholesterol. LDL-cholesterol is calculated from measured values of total cholesterol, triglycerides, and HDL-cholesterol according to the relationship:

LDL-chol $=$ total chol - HDL-chol $-[$ TG $] / 5$

Where [TG]/5 is an estimate of VLDL-cholesterol, and all values are expressed in $\mathrm{mmol} / \mathrm{L}$.

Cholesterol components and triglycerides were analyzed using an Olympus AU400 analyzer.

\section{Statistical Analysis}

Statistical analysis of serum constituents was performed by variance analysis (ANOVA) using the IBM SPSS (Version 20.0, SPSS, Inc., Chicago, IL, USA). Differences between means were determined by a range test $(p<0.01)$. The Pearson correlation coefficient is a measure of the strength of the linear association between two variables.

\section{Results}

The mean age of patients in the control group (32.10 \pm 3.25 ) and the group of patients with therapy included $(31.93 \pm 4.02)$ did not differ significantly. Also, BMI was similar between the two groups. Table 1 presents the percentage of participants by BMI category. $55 \%$ of participants $\left(G_{1}\right)$ and $58 \%$ of participants $\left(G_{2}\right)$ had an ideal body weight. Obesity was noted in $18.66 \%$ of $\mathrm{G}_{1}$ participants and $17.33 \%$ of $\mathrm{G}_{2}$ participants. Moderate obesity is present in $5.33 \%$ of $\mathrm{G}_{1}$ participants and $4 \%$ of $\mathrm{G}_{2}$ participants. $2.66 \%$ of $G_{1}$ and $1.33 \%$ of $G_{2}$ participants had severe obesity.

The mean values of serum biochemical parameters of the participant for both groups are presented in Table 2. 
Table 1 Body weight features of the study participants

\begin{tabular}{|c|c|c|c|c|c|}
\hline & & & Group I & Group II & Total \\
\hline \multirow[t]{2}{*}{ Age (year) } & & $x$ & $32.10 \pm 3.25$ & $31.93 \pm 4.02$ & - \\
\hline & & $N$ & 75 & 75 & 150 \\
\hline BMI $\left(\mathrm{kg} / \mathrm{m}^{2}\right)$ & & $x$ & $25.17 \pm 2.83$ & $24.92 \pm 2.63$ & - \\
\hline \multirow[t]{8}{*}{$\mathrm{BMI}$} & Normal body weight (20-24.9) & $N$ & $55(57.42 \pm 2.31)$ & $58(56.69 \pm 2.72)$ & 113 \\
\hline & & $\%$ & 73.33 & 77.33 & 75.33 \\
\hline & Overweight (25-29.9) & $N$ & $14(71.25 \pm 2.41)$ & $13(70.69 \pm 2.34)$ & 27 \\
\hline & & $\%$ & 18.66 & 17.33 & 18 \\
\hline & Serve obesity (30-39.9) & N & $4(84.13 \pm 1.30)$ & $3(83.55 \pm 2.14)$ & 7 \\
\hline & & $\%$ & 5.33 & 4.0 & 4.66 \\
\hline & Extreme obesity ( $(240)$ & N & $2(98.44 \pm 1.22)$ & $1(98.27)$ & 3 \\
\hline & & $\%$ & 2.66 & 1.33 & 2.0 \\
\hline Total & & $N$ & 75 & 75 & 150 \\
\hline
\end{tabular}

Data are expressed as number $(N)$ and percentage (\%)

Table 2 Overview of serum biochemical parameters in patients with therapy $\left(G_{2}\right)$ and without therapy (de novo, $G_{1}$ ). Data are presented as mean \pm SD

\begin{tabular}{lllll}
\hline Parameters & Group & Mean & Range & Sig. \\
\hline $\mathrm{LH}(\mathrm{IU} / \mathrm{mL})$ & $\mathrm{G}_{1}$ & $13.57 \pm 6.54$ & $3.30-43.00$ & 0.125 \\
& $\mathrm{G}_{2}$ & $12.37 \pm 6.16$ & $1.68-31.10$ & \\
$\mathrm{FSH}(\mathrm{IU} / \mathrm{mL})$ & $\mathrm{G}_{1}$ & $6.29 \pm 2.97$ & $2.04-13.90$ & 0.244 \\
$\mathrm{LH} / \mathrm{FSH}$ & $\mathrm{G}_{2}$ & $5.99 \pm 2.30$ & $1.20-10.69$ & \\
& $\mathrm{G}_{1}$ & $2.56 \pm 1.71$ & $0.62-9.75$ & $0.043^{*}$ \\
Glucose (mmol/L) & $\mathrm{G}_{2}$ & $2.41 \pm 1.72$ & $0.27-8.09$ & \\
& $\mathrm{G}_{1}$ & $6.23 \pm 1.22$ & $3.86-10.21$ & $0.003^{*}$ \\
Insulin (ulU/mL) & $\mathrm{G}_{2}$ & $5.12 \pm 0.62$ & $3.23-6.71$ & \\
& $\mathrm{G}_{1}$ & $19.21 \pm 7.43$ & $6.22-44.00$ & $0.000^{* *}$ \\
IR & $\mathrm{G}_{2}$ & $7.35 \pm 4.21$ & $3.26-15.20$ & \\
& $\mathrm{G}_{1}$ & $3.22 \pm 1.45$ & $1.90-6.60$ & $0.000^{* *}$ \\
Cholesterol (mmol/L) & $\mathrm{G}_{2}$ & $1.42 \pm 0.53$ & $0.35-2.30$ & \\
& $\mathrm{G}_{1}$ & $5.97 \pm 1.13$ & $3.00-7.68$ & $0.002^{*}$ \\
Tryacilglycerol (mmol/L) & $\mathrm{G}_{2}$ & $4.92 \pm 1.82$ & $2.64-6.62$ & \\
& $\mathrm{G}_{1}$ & $1.57 \pm 0.92$ & $0.43-3.95$ & 0.471 \\
HDL (mmol/L) & $\mathrm{G}_{2}$ & $1.22 \pm 0.48$ & $0.42-3.70$ & \\
& $\mathrm{G}_{1}$ & $1.42 \pm 0.37$ & $0.73-2.22$ & 0.769 \\
& $\mathrm{G}_{2}$ & $1.39 \pm 0.43$ & $0.59-2.20$ & \\
LDL (mmol/L) & $\mathrm{G}_{1}$ & $3.56 \pm 0.45$ & $1.27-4.90$ & $0.001^{*}$ \\
& $\mathrm{G}_{2}$ & $2.56 \pm 0.63$ & $1.05-4.20$ & \\
\hline
\end{tabular}

Sig. indicate differences between groups $\left(G_{1}\right.$ vs $\left.G_{2}\right)$

*Statistically significant at $0.05(P<0.05)$ and ** at $0.001(P<0.001)$

De novo patients had higher values of serum biochemical parameters compared to group II. Although intergroup differences were found for all parameters, statistically significant differences were found for LH/ FSH ratio, glucose, insulin, IR, cholesterol, and LDL levels.
Table 3 presents the correlation for $\mathrm{LH}, \mathrm{FSH}$, and LH/ FSH ratio between groups. PCOS patients without therapy had a positive significant correlation of LH with FSH and LH/FSH ratio. A negative significant correlation was observed between FSH and LH/FSH ratio. However, PCOS patients with therapy did not have a significant correlation between LH and FSH, but a significant correlation was found for the LH/FSH ratio: positive correlation with $\mathrm{LH}$ and negative correlation with FSH.

As presented in Table 1, no significant differences were observed for LH, FSH and LH/FSH ratio. Although higher values of hormone and LH/FSH ratio were found in $G_{1}$, the interpolation curve represents a discontinuity for LH and continuity for FSH and LH/FSH ratio (Fig. 1). The discontinuity of $\mathrm{LH}$ values could contribute to the change of LH/FSH ratio and significant correlations between hormone levels presented in Table 3.

The regularity of menstrual cycle (see Table 4) is significantly affected by LH, FSH hormones and the ratio between them. This is exclusively a characteristic of patients in group II, which was not recorded in group I. Participants with a regular menstrual cycle had a lower LH/FSH ratio compared to participants who did not have a regular menstrual cycle $(t=-2.125 ; P=0.029)$.

Analysis of clinical features (Fig. 2) showed that $64 \%$ of G1 participants and $56 \%$ of G2 participants had regular cycles $(P=0.589)$. The prevalence of acne and hirsutism was approximately equal. Comparison of both groups did not show significant differences between the clinical characteristics of women with PCOS.

\section{Discussion}

Polycystic ovary syndrome is present in $6-10 \%$ of women of reproductive age, but the prevalence may be twice as high as the Rotterdam criteria. Studies suggest that 
Table 3 Spearman's rho coefficient corellation

\begin{tabular}{|c|c|c|c|c|c|c|c|}
\hline Groups & & $\mathrm{G}_{1}$ & & & $\mathrm{G}_{2}$ & & \\
\hline Parameters & Corell. & $\mathrm{LH}$ & $\mathrm{FSH}$ & LH/FSH & $\mathrm{LH}$ & FSH & $\mathrm{LH} / \mathrm{FSH}$ \\
\hline \multirow[t]{2}{*}{$\mathrm{LH}$} & $R$ & - & $.307^{\mathrm{a}}$ & $.486^{\mathrm{a}}$ & - & .162 & $.736^{\mathrm{a}}$ \\
\hline & Sig. & . & .007 & .000 & . & .165 & .000 \\
\hline \multirow[t]{2}{*}{$\mathrm{FSH}$} & $R$ & $.307^{\mathrm{a}}$ & - & $-.600^{\mathrm{a}}$ & .162 & - & $-.451^{\mathrm{a}}$ \\
\hline & Sig. & .007 & . & .000 & .165 & . & .000 \\
\hline \multirow[t]{2}{*}{ LH/FSH } & $R$ & $.486^{\mathrm{a}}$ & $-.600^{\mathrm{a}}$ & - & $.736^{\mathrm{a}}$ & $-.451^{\mathrm{a}}$ & - \\
\hline & Sig. & .000 & .000 & & .000 & .000 & \\
\hline
\end{tabular}

${ }^{\text {a }}$ Correlation is significant at the 0.01 level

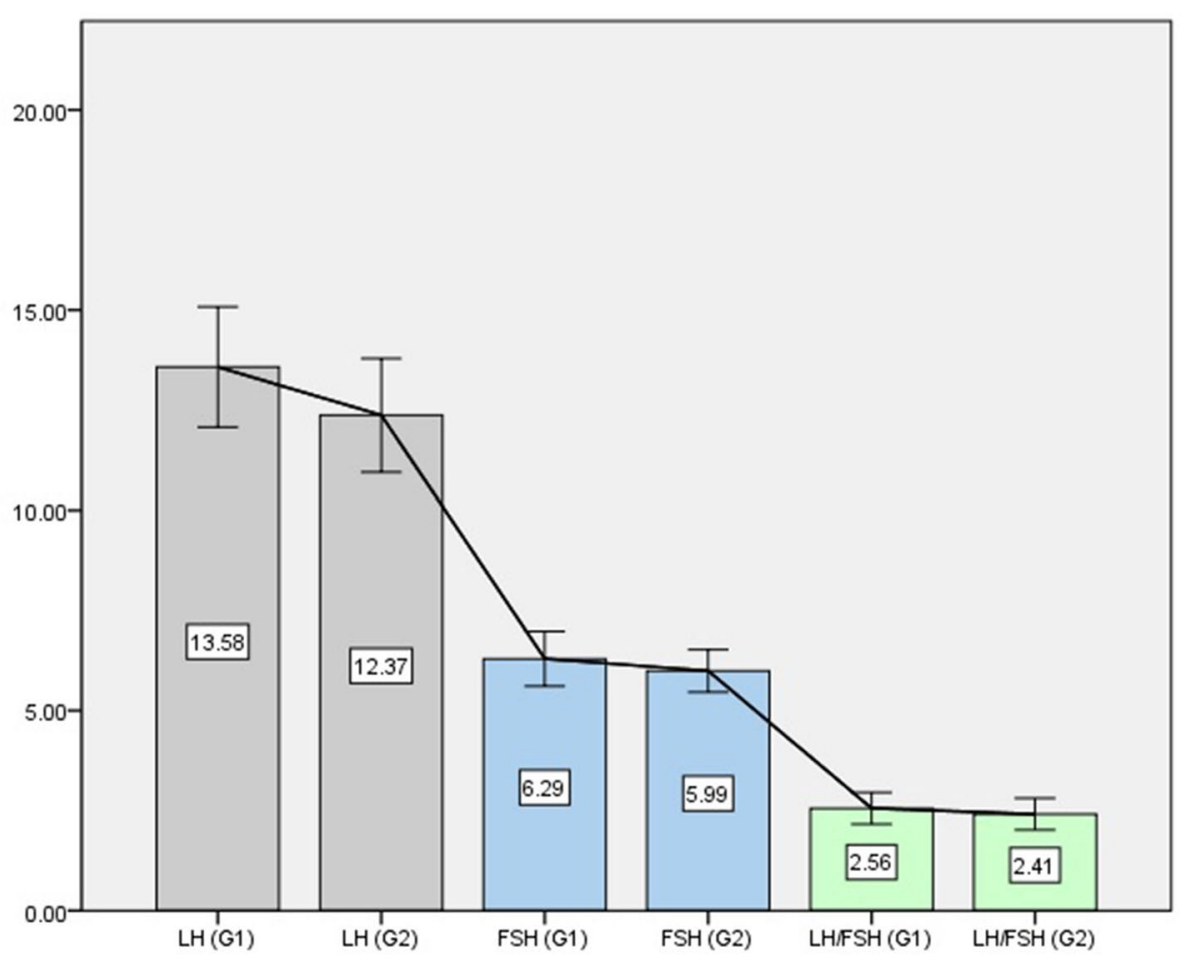

Fig. 1 Linear interpolation results in discontinuities of $\mathrm{LH}$

congenital abnormalities of ovarian steroidogenesis and follicle development play a role in the development of PCOS [11, 23, 24]. In our study, women with therapy for PCOS had higher predispositions for ideal body weight and reduced severe obesity compared to women without therapy. McCartney and Marshall [11] reported the presence of obesity in $50-80 \%$ of women with PCOS, and the risk increases with age and development of diabetes. Obesity worsens metabolic and reproductive outcomes in PCOS, such as insulin resistance, squamous cell sensitization to LH stimulation, and functional ovarian hyperandrogenism, by regulating androgen production in the ovaries [25]. Wiweko et al. [26] reported that $50.4 \%$ of patients were obese, which is similar to our results, but women had a lower mean age compared to our results. Chen et al. [27] investigated the body mass index for women with PCOS and compared metabolic abnormalities between women with PCOS and control women in southern China. They found that $34.63 \%$ of women have a BMI above $23 \mathrm{~kg} / \mathrm{m}^{2}$, which we also found in our study.

Szosland et al. [28] did not note any differences in the IR and lipid profile between women diagnosed with PCOS and those without PCOS. However, our results show significant differences between the two groups of participants, as well as lower values of serum markers in women with therapy. Levels of LH and FSH did not 
Table 4 Regression model for normal menstrual cycles compared to independent variables

\begin{tabular}{|c|c|c|c|c|c|c|}
\hline \multirow[t]{2}{*}{ Groups } & & \multicolumn{2}{|c|}{ Unstandardized Coefficients } & \multirow{2}{*}{$\begin{array}{l}\text { Standardized } \\
\text { Coefficients } \\
\text { Beta }\end{array}$} & \multirow[t]{2}{*}{$t$} & \multirow[t]{2}{*}{ Sig. } \\
\hline & & $B$ & Std. Error & & & \\
\hline \multirow[t]{6}{*}{$\mathrm{G}_{1}$} & (Constant) & 0.509 & 0.553 & & 0.943 & 0.367 \\
\hline & $\mathrm{BMI}$ & -0.019 & 0.013 & -0.184 & -1.371 & 0.182 \\
\hline & $\mathrm{LH} / \mathrm{FSH}$ & 0.049 & 0.059 & 0.123 & 0.865 & 0.382 \\
\hline & Glucose & 0.104 & 0.071 & 0.320 & 1.638 & 0.076 \\
\hline & Insulin & 0.020 & 0.032 & 0.375 & 0.541 & 0.590 \\
\hline & IR & -0.252 & 0.273 & -0.674 & -0.900 & 0.359 \\
\hline \multirow[t]{6}{*}{$\mathrm{G}_{2}$} & (Constant) & 0.429 & 0.720 & & 0.560 & 0.531 \\
\hline & $\mathrm{BMl}$ & 0.001 & 0.016 & 0.020 & 0.072 & 0.923 \\
\hline & LH/FSH & -0.119 & 0.054 & -0.290 & -2.125 & $0.029^{*}$ \\
\hline & Glucose & 0.121 & 0.076 & 0.195 & 1.182 & 0.292 \\
\hline & Insulin & 0.064 & 0.079 & 0.603 & 1.113 & 0.395 \\
\hline & $\mathbb{R}$ & -0.640 & 0.586 & -0.640 & -1.520 & 0.192 \\
\hline
\end{tabular}

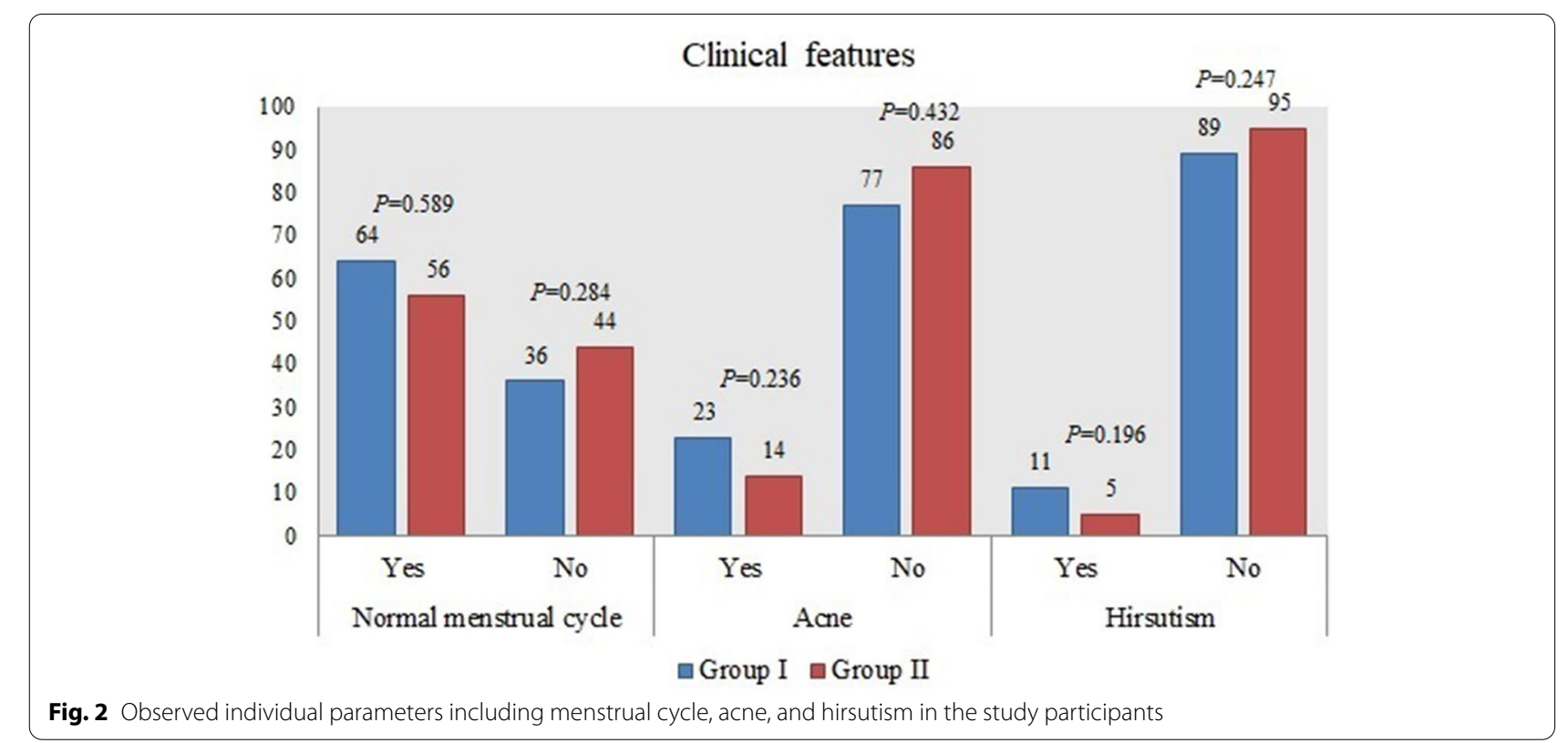

differ significantly between groups, except for the LH/ FSH ratio. Malini and George [29] reported that there was a difference in the range of $\mathrm{LH}$ and FSH production, as well as a higher LH/FSH ratio as the most common clinical manifestation of women diagnosed with PCOS. Nath et al. [30] found an elevated LH/FSH ratio in 70.58\% of women diagnosed with PCOS. Therefore, the authors suggest that the LH/FSH ratio is one of the characteristic attributes of women with PCOS. However, Esmaeilzadeh et al. [31] did not observe an association between LH and FSH levels with the LH/FSH ratio. In our study, we recorded a significant relationship between hormone levels and the LH/FSH ratio. This correlation is more present in the group of patients without therapy. No correlation between LH and FSH was found in the group of patients treated with PCOS, but it was significantly different for the LH/FSH ratio. The reason for this may be an effective therapy in regulating serum hormone levels. However, the results suggest the presence of LH level discontinuity as indicated by the interpolation curve. These LH levels are a possible reason for the positive correlation with $\mathrm{LH}$ and the negative correlation with FSH. The neuroendocrine feature of PCOS is rapid LH pulsatility, which favors the pituitary synthesis of LH over that of FSH and contributes to the increased LH levels and LH/ FSH ratio typical of PCOS [16]. 
Esmaeilzadeh et al. [31] found a large number of participants diagnosed with PCOS, among whom patients with acne were $31.4 \%$, while the incidence of hirsutism among patients was high at $78.9 \%$. The previous values are higher compared to our study. Also, the irregularity of the menstrual cycle, the frequency of acne, and hirsutism are lower in patients with therapy for PCOs. However, no significant differences were found. We believe that a study with a larger number of patients would provide significant statistical differences, especially if long-term therapy and continuous control of patients.

It is estimated that about $50-80 \%$ of patients with PCOS develop insulin resistance, which correlates with insulin production [32]. Dunaif and Thomas [33] suggested that insulin resistance associated with PCOS has a different genetic basis than that associated with obesity or the presence of insulin-independent diabetes. Rosenbaum et al. [34] reported that IR was associated with a reduction in the GLUT-4 transporter in adipocytes in patients with PCOS, but was independent of obesity and not related to a reduction in insulin receptors. Fruzzettti et al. [35] noted that treatment of patients with metformin and inositol leads to decreased glucose levels and increased insulin sensitivity. Also, in our study, patients with PCOS were treated with metformin, which caused lower glucose levels and insulin sensitivity. Although health improvements were noted during treatment, no differences in the presence of acne and hirsutism between treated and untreated patients were observed. Hyperinsulinemia in obese and normal weight women with PCOS shows insulin resistance and increased LDL levels and decreased HDL [36].

Our de novo group of women had significantly higher cholesterol and LDL values compared to $\mathrm{G}_{2}$. $\mathrm{Ng}$ et al. [37] reported that the waist-to-hip ratio and high triglycerides were associated with PCOs progression to type 2 diabetes mellitus. Triglyceride levels may be age-related because older women $(54.1 \pm 6.7)$ were included in the study, which was not the case in our study. Also, we did not find significant differences in triglycerides between groups. Sharma et al. [38] examined the effect of metformin on insulin, blood sugar, and body mass index. They found that metformin significantly lowered insulin levels in patients with PCOS in both obese and normal-weight individuals, suggesting its usefulness in the treatment of PCOS. These results were also confirmed in our study. In comparison with women with PCOS and normal cholesterol levels, women with mild hypercholesterolemia had a higher BMI, higher insulin concentration, and presence of IR [39]. Also, no correlation was found between hormone levels and cholesterol concentrations. Although clinical signs were present, no statistically significant differences were found in the presence of acne, hirsutism, and irregular cycle in our study. Fonseka et al. [40] have not found an association between hirsutism and visceral adiposity, but the incidence of acne and hirsutism occurs in equal proportions in women with PCOS in India [41]. Hyperandrogenemia, in addition to the presence of hirsutism (60-83\%), is characterized by the appearance of acne in $11-43 \%$ of women [42]. In a study by Ramanand et al. [41] a total of $12.5 \%$ of patients reported abnormal hair growth; clinically $44.16 \%$ of women had hirsutism. In a study by Sharma et al. [38], 62\% of patients had a positive family history of diabetes mellitus and obesity, which is much higher than in our study. In a study by Battalgia et al. [43], a high prevalence of $93 \%$ was found in daughters with PCOS whose mothers also had PCOS. Such a high prevalence may be due to the specific selection of participants. Similarly, Dunaif and Thomas [33] reported that PCOS and hyperandrogenemia were present in approximately $50 \%$ of the sisters of affected women. Using linear regression, it was found that in patients taking therapy for PCOS the regularity of menstrual cycles significantly depends on the LH/FSH ratio. The LH/FSH ratio in women with a regular menstrual cycle was lower than in women without a regular menstrual cycle.

\section{Conclusions}

PCOS cause irregularities of the menstrual cycle, the appearance of clinical manifestations, especially changes of LH/FSH ratio. De novo patients which are not included in therapy had significantly higher levels of glucose, insulin, IR, cholesterol, LDL, and LH/FSH ratio. There was a positive or negative correlation between $\mathrm{LH}$ and $\mathrm{FSH}$, as well as the correlation between hormone levels and LH/ FSH ratio in the de novo patients. No significant correlation was found between LH and FSH in patients with therapy. Hormone therapy has a positive effect on serum hormone levels and insulin resistance. Also, the correlation between the hormone and the LH/FSH ratio changes significantly. However, long-term treatment and ordinary control of patients, as well as the involvement of a large number of participants might give significant differences, which is a limitation of this study.

\section{Abbreviations \\ 11ß-HSD: $11 \beta$-Hydroxysteroid dehydrogenase; ACTH: Adrenocorticotropic hormone; ATP: Adenosine triphosphate; BMI: Body mass index; ECLIA: Electro- chemiluminescence immunoassay; FSH: Follicle-stimulating hormone; $\mathrm{GnRH}$ : Gonadotropin-releasing hormone; HDL: High-density lipoprotein; HOMA: Homeostatic assessment model; IR: Insulin resistance; LDL: Low-density lipoprotein; LH: Luteinizing hormone; MetS: Metabolic syndrome; NAD: Nico- tinamide adenine dinucleotide; NADH: Nicotinamide adenine dinucleotide hydrogen; PCOS: Polycystic ovarian syndrome.}

\section{Acknowledgements}

The authors would like to express their gratitude to those who have helped in the Agram Polyclinic, Sarajevo, Bosnia and Herzegovina. 


\section{Authors' contributions}

MMB contributed to the methodology, design, and drafting of the manuscript. $\mathrm{MB}$ contributed to the formal analysis, conceptualization, statistical analysis, and drafting of the manuscript. DS contributed to the conceptualization, validation, data curation, writing of the original draft, writing of the review, and editing. All authors have read and approved the manuscript.

\section{Funding}

Not applicable.

\section{Availability of data and materials}

Not applicable.

\section{Declarations}

\section{Ethics approval and consent to participate}

All procedures performed in studies involving human participants were in accordance with the ethical standards of the institutional and/or national research committee and with the 1964 Helsinki Declaration and its later amendments or comparable ethical standards. Approval for the research was given by the Ethics Committee at the Agram Polyclinic (2314-18/2019). After presenting the purpose of the study to suitable participants who met the criteria for participation, written consent was obtained from each participant.

\section{Consent for publication}

Not applicable.

\section{Competing interests}

The authors declare that they have no conflict of interest.

\section{Author details}

1 Department of Biology, Faculty of Science, University of Sarajevo, Sarajevo, Bosnia and Herzegovina. ${ }^{2}$ Polyclinic Agram, Trg Međunarodnog prijateljstva 21, Sarajevo, Bosnia and Herzegovina.

Received: 5 February 2021 Accepted: 7 October 2021

Published online: 28 October 2021

\section{References}

1. Catteau-Jonard S, Dewailly D (2013) Pathophysiology of polycystic ovary syndrome: the role of hyperandrogenism. Front Horm Res 40:22-27

2. Carmina E, Campagna AM, Lobo RA (2013) Emergence of ovulatory cycles with aging in women with polycystic ovary syndrome (PCOS) alters the trajectory of cardiovascular and metabolic risk factors. Hum Reprod 28(8):2245-2252

3. Madnani N, Khan K, Chauhan PP (2013) Polycystic ovarian syndrome. Indian J Dermatol Venereol Leprol 79:310-321. https://doi.org/10.4103/ 0378-6323.110759

4. Fauser BC, Tarlatzis BC, Rebar RW, Legro RS, Balen AH, Lobo R et al (2012) Consensus on women's health aspects of polycystic ovary syndrome (PCOS): the Amsterdam ESHRE/ASRM-Sponsored 3rd PCOS Consensus Workshop Group. Fertil Steril 97(1):28-38. https://doi.org/10.1016/j.fertn stert.2011.09.024

5. Conway G, Dewailly D, Diamanti-Kandarakis E, Eskobar-Morreale HF Franks S, Gambineri A et al (2014) The polycystic ovary syndrome: an endocrinological perspective from the European Society of Endocrinology. Eur J Endocrinol 171(4):1-29. https://doi.org/10.1530/ EJE-14-0253

6. DeUgarte CM, Bartolucci AA, Azziz R (2005) Prevalence of insulin resistance in the polycystic ovary syndrome using the homeostasis model assessment. Fertil Steril 83(5):1454-1460. https://doi.org/10.1016/j.fertn stert.2004.11.070

7. Vgontzas AN, Legro RS, Bixler EO, Grayev A, Kales A, Chrousos GP (2001) Polycystic ovary syndrome is associated with obstructive sleep apnea and daytime sleepiness: Role of insulin resistance. J Clin Endocrinol Metab 86(2):517-520. https://doi.org/10.1210/jcem.86.2.7185
8. Patel S (2018) Polycystic ovary syndrome (PCOS), an inflammatory, systemic, lifestyle endocrinopathy. J Steroid Biochem Mol Biol 182:27-36. https://doi.org/10.1016/j.jsbmb.2018.04.008

9. Azziz R, Carmina E, Dewailly D, Diamanti-Kandarakis E, Escobar-Morreale HF, Futterweit W et al (2009) The androgen excess and PCOS society criteria for the polycystic ovary syndrome: the complete task force report. Fertil Steril 91(2):456-488. https://doi.org/10.1016/j.fertnstert.2008.06.035

10. Rotterdam ESHRE/ASRM (2004) Revised 2003 consensus on diagnostic criteria and long-term health risks related to polycystic ovary syndrome. Rotterdam ESHRE/ASRM-Sponsored PCOS Consensus Workshop Group. Fertil Steril 81(1):19-25. https://doi.org/10.1016/j.fertnstert.2003

11. McCartney CR, Marshall CJ (2016) Polycystic Ovary Syndrome. N Engl J Med 375(1):54-64. https://doi.org/10.1056/NEJMcp1514916

12. Glintborg D (2016) Endocrine and metabolic characteristics in polycystic ovary syndrome. Dan Med J. 63(4):B5232

13. Cuhaci N, Polat SB, Evranos B, Ersoy R, Cakir B (2014) Gynecomastia: clinical evaluation and management. Indian J Endocrinol Metab 18:150-158. https://doi.org/10.4103/2230-8210.129104

14. Tsutsumi R, Webster NJG (2009) GnRH pulsatility, the pituitary response and reproductive dysfunction. Endocrine J 56(6):729-737. https://doi.org/ 10.1507/endocrj.k09e-185

15. Klein DA, Poth MA (2013) Amenorrhea: an approach to diagnosis and management. Am Fam Physician 87(11):781-788

16. Blank SK, McCartney CR, Marshall JC (2006) The origins and sequelae of abnormal neuroendocrine function in polycystic ovary syndrome. Hum Reprod Update 12:351-361. https://doi.org/10.1093/humupd/dml017.

17. Dumesic DA, Richards JS (2013) Ontogeny of the ovary in polycystic ovary syndrome. Fertil Steril 100(1):23-38. https://doi.org/10.1016/j.fertn stert.2013.02.011

18. Yang O, Kim HL, Weon Jl, Seo YR (2015) Endocrine-disrupting chemicals: review of toxicological mechanisms using molecular pathway analysis. J Cancer Prev 20(1):12-24. https://doi.org/10.15430/JCP.2015.20.1.12

19. Draper N, Walker EA, Bujalska IJ, Tomlinson JW, Chalder SM, Arlt W et al (2003) Mutations in the genes encoding 11 beta-hydroxysteroid dehydrogenase type 1 and hexose-6-phosphate dehydrogenase interact to cause cortisone reductase deficiency. Nat Genet 34(4):434-439

20. Allain CC, Poon LS, Chan CS, Richmond W, Fu PC (1974) Enzymatic determination of total serum cholesterol. Clin Chem 20(4):470-475. https://doi. org/10.1093/clinchem/20.4.470

21. Saadia Z (2020) Follicle stimulating hormone (LH:FSH) ratio in polycystic ovary syndrome (PCOS)-obese vs. non-obese women. Med Arch 74(4):289-293. https://doi.org/10.5455/medarh.2020.74.289-293

22. Kim JJ, Choi YM (2013) Dyslipidemia in women with polycystic ovary syndrome. Obstet Gynecol Sci 56(3):137-142. https://doi.org/10.5468/ ogs.2013.56.3.137

23. Dumesic DA, Oberfield SE, Stener-Victorin E, Marshall JC, Laven JS, Legro RS (2015) Scientific statement on the diagnostic criteria, epidemiology, pathophysiology, and molecular genetics of polycystic ovary Syndrome. Endocr Rev 36(5):487-525. https://doi.org/10.1210/er.2015-1018

24. Spritzer PM (2014) Polycystic ovary syndrome: reviewing diagnosis and management of metabolic disturbances. Arq Bras Endocrinol Metab 58(2):182. https://doi.org/10.1590/0004-2730000003051

25. Glueck CJ, Goldenberg N (2019) Characteristics of obesity in polycystic ovary syndrome: Etiology, treatment, and genetics. Metabolism 92:108-120. https://doi.org/10.1016/j.metabol.2018.11.002

26. Wiweko B, Indra I, Susanto C, Natadisastra M, Hestiantoro A (2018) The correlation between serum AMH and HOMA-IR among PCOS phenotypes. BMC Res Notes 11(1):114. https://doi.org/10.1186/ s13104-018-3207-y

27. Chen X, Ni R, Mo Y, Li L, Yang D (2010) Appropriate BMl levels for PCOS patients in Southern China. Hum Reprod 5(1):1295-1302. https://doi.org/ 10.1093/humrep/deq028

28. Szosland K, Karzkowiak A, Lewinski A (2018) Metabolic characteristics of women diagnosed with polycystic ovary syndrome (PCOS) according to the Rotterdam criteria - our own experience. Neuro Endocrinol Lett 39(6):434-440

29. Malini NA, George KR (2018) Evaluation of different ranges of LH:FSH ratios in polycystic ovarian syndrome (PCOS) - Clinical based case control study. Gen Comp Endocrinol 260:51-57. https://doi.org/10.1016/j.ygcen. 2017.12.007 
30. Nath CK, Barman B, Das A, Rajkhowa P, Baruah P, Baruah M, Baruah A (2019) Prolactin and thyroid stimulating hormone affecting the pattern of LH/FSH secretion in patients with polycystic ovary syndrome: A hospital-based study from North East India. J Family Med Primary Care 8(1):256-260. https://doi.org/10.4103/jfmpc.jfmpc_281_18

31. Esmaeilzadeh S, Andarieh MG, Ghadimi R, Delavar MA (2014) Body mass index and gonadotropin hormones (LH \& FSH) associate with clinical symptoms among women with polycystic ovary syndrome. Glob J Health Sci 7(2):101-106. https://doi.org/10.5539/gihs.v7n2p101

32. Diamanti-Kandarakis E, Dunaif A (2012) Insulin resistance and the polycystic ovary syndrome revisited: an update on mechanisms and implications. Endocrine Rev 33(6):981-1030. https://doi.org/10.1210/er. 2011-1034

33. Dunaif A, Thomas A (2001) Current concepts in the polycystic ovary syndrome. Annu Rev Med 52:401-419. https://doi.org/10.1146/annurev. med.52.1.401

34. Rosenbaum D, Haber RS, Dunaif A (1993) Insulin resistance in polycystic ovary syndrome: Decreased expression of GLUT-4 glucose transporters in adipocytes. Am J Physiol 264:197-202. https://doi.org/10.1152/ajpendo. 1993.264.2.E197

35. Fruzzetti F, Perini D, Russo M, Bucci F, Gadducci A (2017) Comparison of two insulin sensitizers, metformin and myo-inositol, in women with polycystic ovary syndrome (PCOS). Gynecol Endocrinol 33:39-42. https:// doi.org/. https://doi.org/10.1080/09513590.2016.1236078

36. Goodman NF, Cobin RH, Futterweit W, Glueck JS, Legro RS, Carmina E (2015) American association of clinical endocrinologists, American College of Endocrinology, and androgen excess and PCOS society disease state clinical review: Guide to the best practices in the evaluation and treatment of polycystic ovary syndrome - Part 1. Endocr Pract 21(11):1291-1300. https://doi.org/10.4158/EP15748.DSC

37. Ng NYH, Jiang G, Cheung LP, Zhang Y, Tam CHT, Luk OAY (2019) Progression of glucose intolerance and cardiometabolic risk factors over a decade in Chinese women with polycystic ovary syndrome: A case-control study. PLoS Med 16(10):e1002953. https://doi.org/10.1371/journal.pmed. 1002953

38. Sharma N, Siriesha LY, Kaur A, Ahuja VK (2019) Effect of metformin on insulin levels, blood sugar, and body mass index in polycystic ovarian syndrome cases. J Family Med Prim Care 8(8):2691-2695. https://doi.org/ 10.4103/jfmpc.jfmpc_490_19

39. Pergialiotis V, Trakakis E, Chrelias C, Papantoniou N, Hatziagelaki E (2018) The impact of mild hypercholesterolemia on glycemic and hormonal profiles, menstrual characteristics and the ovarian morphology of women with polycystic ovarian syndrome. Horm Mol Biol Clin Investig 34(3) ):/j/ hmbci.2018.34.issue-3/hmbci-2018-0002/hmbci-2018-0002.xml. https:// doi.org/10.1515/hmbci-2018-0002

40. Fonseka S, Subhani B, Wijeyaratne CN, Gawarammana IB, Kalupahana NS, Ratnatunga N et al (2019) Association between visceral adiposity index, hirsutism and cardiometabolic risk factors in women with polycystic ovarian syndrome: A cross-sectional study. Ceylon Med J 64(3):111-117. https://doi.org/10.4038/cmj.v64i3.8958

41. Ramanand SJ, Ghongane BB, Ramanand JB, Patwardhan MH, Ghanghas RR, Jain SS (2013) Clinical characteristics of polycystic ovary syndrome in Indian women. Indian J Endocrinol Metab (17)1:138-145. https://doi.org/ 10.4103/2230-8210.107858

42. Archer JS, Chang RJ (2004) Hirsutism and acne in polycystic ovary syndrome. Best Practice Res Clinic Obstetrics Gynaecol 18(5):737-754. https://doi.org/10.1016/j.bpobgyn.2004.05.007

43. Battaglia C, Regnani G, Mancini F, Lughetti L, Flamingi C, Venturoli S (2002) Polycystic ovaries in childhood: a common finding in daughters of PCOS patients. Hum Reprod 17(3):771-776. https://doi.org/10.1093/ humrep/17.3.771

\section{Publisher's Note}

Springer Nature remains neutral with regard to jurisdictional claims in published maps and institutional affiliations.

\section{Submit your manuscript to a SpringerOpen ${ }^{\circ}$ journal and benefit from:}

- Convenient online submission

- Rigorous peer review

- Open access: articles freely available online

- High visibility within the field

- Retaining the copyright to your article

Submit your next manuscript at $\boldsymbol{\nabla}$ springeropen.com 